\title{
Asiatic Acid Induces Apoptosis and Autophagy and Reduces MiR-17 and MiR-21 Expression in Pancreatic Cancer Cell Lines
}

\author{
Yoon-Gyung Jo', Myoungjae Kim¹, Hyeji Shin ${ }^{2}$, Ki Yong Lee ${ }^{2, *}$, and Eun Joo Lee ${ }^{1, *}$ \\ ${ }^{I}$ College of Pharmacy and Wonkwang Oriental Medicines Research Institute, Wonkwang University, Iksan, Republic of Korea \\ ${ }^{2}$ College of Pharmacy, Korea University, Sejong, Republic of Korea
}

\begin{abstract}
This study investigated the cytotoxic effects and mechanism of action of asiatic acid in pancreatic cancer cell lines. First, we confirmed the cell viability of MIA PaCa- 2 and PANC-1 cells after asiatic acid administration for 48 and $72 \mathrm{~h}$. The viability of MIA PaCa-2 and PANC-1 cells decreased in a dose-dependent manner following asiatic acid administration. To investigate the underlying mechanism, we performed a terminal deoxynucleotidyl transferase dUTP nick end labeling (TUNEL) assay, annexin V assay, and western blotting. Asiatic acid induced apoptosis and autophagy through activation of AMP-activated protein kinase (AMPK) and inhibition of mammalian target of rapamycin (mTOR) in MIA PaCa-2 cells. Finally, the expression of miR-17 and miR-21, known as oncogenes in pancreatic cancer, was decreased by asiatic acid. These results indicate that asiatic acid has potential as a new therapeutic agent against pancreatic cancer.
\end{abstract}

Keywords - Asiatic acid, Pancreatic cancer, Apoptosis, Autophagy, MicroRNA

\section{Introduction}

Pancreatic cancer is the fourth leading cause of cancerrelated deaths at all ages. It has a 5-year survival rate of less than $7 \%$. $^{1,2}$ The mortality rate of pancreatic cancer is high, but its cause or underlying mechanisms are not fully understood. ${ }^{3}$ Surgical resection, chemotherapy, and radiotherapy were used as the main therapeutic options, ${ }^{4,5}$ with gemcitabine being the typical chemotherapeutic agent used for pancreatic cancer. However, the response rate to gemcitabine is less than $10 \%{ }^{6}$ Thus, novel agents to sensitize pancreatic cancer cells are needed.

Asiatic acid is a pentacyclic triterpene isolated from the Centella asiatica, which is a plant used in traditional medicine in Asia. ${ }^{7}$ It displays antioxidant, anti-inflammatory, and neuroprotective properties. ${ }^{8,9}$ Several studies have shown that asiatic acid induces apoptosis in Hep G2 cells causing the release of $\mathrm{Ca}^{2+}$ and up-regulation of $\mathrm{p} 53 .^{10}$ Furthermore, asiatic acid can prevent the growth of HT-29

\footnotetext{
*Author for correspondence

Eun Joo Lee, College of Pharmacy and Wonkwang Oriental Medicines Research Institute, Wonkwang University, Iksan 54538, Republic of Korea.

Tel.: +82 63850 6801; E-mail: ejlee7@wku.ac.kr

Ki Yong Lee, College of Pharmacy, Korea University, 2511 Sejongro, Sejong 30019, Republic of Korea.

Tel.: +82-44-860 1623; E-mail: kylee11@korea.ac.kr
}

cells by inducing apoptosis and affecting B-cell lymphoma 2 (Bcl-2) and B-cell lymphoma-extralarge (Bcl-xL) expression. ${ }^{11}$ It has also been reported that asiatic acid inhibits angiogenesis through VEGF and human gliomas in endothelial cells. ${ }^{12}$

As though the potential of asiatic acid in cancer, antiproliferative effect of asiatic acid and the underlying mechanism(s) have not evaluated in pancreatic cancer. In this study, the cytotoxic effects of asiatic acid were investigated in pancreatic cancer cell lines and the molecular mechanisms were identified using the TUNEL assay, annexin $\mathrm{V}$ assay, western blotting, and miRNA analysis.

\section{Experimental}

General experimental procedure - Human pancreatic cancer cell lines, MIA PaCa-2 and PANC-1 were purchased from the American Type Culture Collection (ATCC, Manassas, VA, US). MIA PaCa-2 and PANC-1 were cultured in Dulbecco's modified Eagle's medium (DMEM; Hyclone, Waltham, MA, USA) with 10\% Fetal bovine serum (FBS; Hyclone, Waltham, MA, USA) and $1 \%$ penicillin/streptomycin (Gibco, Invitrogen Inc., Carlsbad, CA, USA) at $37{ }^{\circ} \mathrm{C}$ with $5 \% \mathrm{CO}_{2}$. Asiatic acid was purchased from Sigma-Aldrich (St.Louis, MO, U.S.A.) with a purity of $97 \%$. 
Water soluble tetrazolium salt-1 (WST-1) assay Asiatic acid is dissolved in dimethyl sulfoxide (DMSO) at $60 \mathrm{mM}$ as a stock solution and stored at $-20^{\circ} \mathrm{C}$. The cancer cell lines were seeded in $100 \mu \mathrm{L}$ of medium at $5 \times$ $10^{3}$ cells per well in 96-well plates. Cells were incubated for $24 \mathrm{~h}$, then treated with asiatic acid at various concentrations $(0,20,40$ and $60 \mu \mathrm{M})$ and $0.1 \%(\mathrm{v} / \mathrm{v})$ DMSO as a negative control. After 48 and $72 \mathrm{~h}, 10 \mu \mathrm{L}$ of WST-1 (Roche, Mannheim, Germany) reagent was added to each well and incubated for $2 \mathrm{~h}$ at $37^{\circ} \mathrm{C}$. Absorbance was measured at $450 \mathrm{~nm}$ using a microplate reader. Cell viability was calculated as a percent of the control value and mean values were averaged for three wells. This experiment was repeated three times.

Western blotting - MIA PaCa- 2 cells $\left(5 \times 10^{5}\right.$ per $1 \mathrm{ml}$ in $10 \mathrm{~cm}^{2}$ culture dish) were treated with asiatic acid at various concentrations $(0,20,40$, and $60 \mu \mathrm{M})$ for $48 \mathrm{~h}$. Cells were treated with $1 \mathrm{~mL}$ radioimmunoprecipitation assay (RIPA) buffer (Thermo Scientific, Waltham, MA, USA) with added phosphatase inhibitor (Roche, Mannheim, Hermany) on ice for $30 \mathrm{~min}$ for lysis. The bicinchoninic acid (BCA) Protein Assay Kit (Thermo Scientific, USA) was used to measure total protein concentration compared to a protein standard; $30 \mu \mathrm{g}$ of total protein was loaded on SDS-PAGE and transferred onto polyvinylidene difluoride (PVDF) membranes. After blocking in 5\% nonfat dry milk in Tris buffered saline with Tween-20 (TBST) for $1 \mathrm{~h}$, the membranes were incubated overnight at $4{ }^{\circ} \mathrm{C}$ with primary antibodies: anti-human-LC3II, mTOR, phosphomTOR, AMPK, phospho-AMPK, p38, phopho-p38, caspase-3, cleaved caspase-3, cleaved poly ADP ribose polymerase (PARP), and alpha-tubulin from Cell Signaling Technology (Beverly, Mass., USA), phosphatase and tensin homolog (PTEN) from Bethly Laboratories (Montgomery, TX, USA) and Bcl-2 from Enzo Life Sciences (Farmingdale, NY, USA). Next, membranes were incubated for $1 \mathrm{~h}$ with secondary antibodies: anti-rabbit from Thermo Scientific (Waltham, MA, USA), and anti-mouse from Bethly Laboratories (Montgomery, TX, USA). Protein bands were detected with an ECL solution kit purchased from Thermo Scientific (Waltham, Ma, USA) and the relative expression of protein bands was analyzed with the FluoroChem E image analyzer (Cell Bioscience, Santa Clara, CA, USA).

TUNEL assay - MIA PaCa- 2 cells $\left(1.5 \times 10^{4}\right.$ cells/200 $\mu \mathrm{L}$ ) were seeded into a Chamber Slide (Lab Tek Chamber Slide) for $24 \mathrm{~h}$. Cells were treated with asiatic acid at $\mathrm{IC}_{50}$ and $\mathrm{HSW} 345^{13}$ at $\mathrm{IC}_{50}$ as a positive control for apoptosis. After incubation for $48 \mathrm{~h}$, the cells were fixed with $100 \mu \mathrm{L}$ of $4 \%$ paraformaldehyde, and then the TUNEL assay was performed using the In Situ Cell Death Detection Kit (Roche, Mannheim, Germany).

Annexin V assay - MIA PaCa- 2 cells $\left(4 \times 10^{5}\right.$ cells/ $\mathrm{mL}$ ) were seeded onto $60 \mathrm{~mm}$ dishes. The following day, the cells were treated with asiatic acid at $0,20,40$ and 60 $\mu \mathrm{M}$ for $48 \mathrm{~h}$. DMSO was used as a negative control. After incubation, cells were fixed and stained using the Muse ${ }^{\circledR}$ Annexin V and Dead Cell Assay Kit (Merck Millipore, Billerica, USA) using the supplier's protocol.

Total RNA extraction - MIA PaCa- 2 cells $\left(4 \times 10^{5}\right.$ cells/well) were seeded on $60 \mathrm{~mm}$ dishes. The following day, cells were treated with asiatic acid at $60 \mu \mathrm{M}$ and incubated for 48 and $72 \mathrm{~h}$. Cells were treated and incubated with DMSO as a negative control. After incubation, the total RNA was extracted using a Trizol reagent (Invitrogen, CA, USA) using the supplier's protocol.

TaqMan miRNA assay - To examine miRNA expression, the TaqMan miRNA assay was performed. A total 50 ng RNA was converted to cDNA using the TaqMan ${ }^{\circledR}$ microRNA Reverse Transcription Kit (Applied Biosystems) following the manufacturer's protocol. Real-time PCR was performed in triplicates and the $2^{-\Delta \Delta C T}$ method was used for the relative quantitation of samples. Data was normalized with the small nuclear RNA, RNU6B gene.

Statistical analysis - All data are represented as the mean \pm standard deviation (SD) of three independent experiments. Significant differences among the groups were determined using a t-test $\left({ }^{*} p \leq 0.05 ;{ }^{* *} p \leq 0.01\right.$ and ${ }^{* * *} p \leq 0.001$ versus the negative control group).

\section{Result and Discussion}

In order to investigate the cytotoxic effect of asiatic acid (Fig. 1) on pancreatic cancer cells, MIA PaCa-2 and PANC-1 cells were exposed to various concentrations of asiatic acid $(0,20,40$, and $60 \mu \mathrm{M})$ for 48 and $72 \mathrm{~h}$ (Fig. 2). Cell viability was analyzed using the WST-1 assay. The viability of MIA PaCa- 2 cells decreased by 93.3 , 84.6 , and $30.2 \%$ of control levels at increasing doses after $48 \mathrm{~h}$. The cell viability of PANC-1 cells decreased by $88.8,85.5$, and $68.3 \%$ of control levels at increasing doses after $48 \mathrm{~h}$. The viability of MIA PaCa-2 cells was reduced by 41.8 and $13.6 \%$ of control levels at 40 and $60 \mu \mathrm{M}$, respectively, after $72 \mathrm{~h}$. The viability of PANC-1 cells dropped by $93.7,77.6$, and $72.1 \%$ at increasing doses after $72 \mathrm{~h}$. The viability of both cell lines decreased in a dose-dependent manner, most prominently at $60 \mu \mathrm{M}$. $\mathrm{IC}_{50}$ of asiatic acid in MIA PaCa-2 was $52.7 \mu \mathrm{M}$. As the cytotoxic effect was more evident in MIA PaCa-2 than in 
<smiles>C[C@H]1CCC2(C(=O)O)CC[C@]3(C)C(=CCC4[C@@]5(C)C[C@H](O)[C@@H](O)[C@](C)(CO)[C@@H]5CC[C@]43C)C2[C@@H]1C</smiles>

Fig. 1. The chemical structure of asiatic acid.

PANC-1 cells, subsequent experiments were performed with MIA PaCa-2 cells.

Tang et al. reported that asiatic acid induced cell growth inhibition and apoptosis through a mitochondrial death cascade in colon cancer. ${ }^{14} \mathrm{Wu}$ et al. also found that asiatic acid induced apoptosis in HL-60 human leukemia cells by modulating the Bcl-2 family. ${ }^{15}$ The TUNEL assay is a method used for detecting DNA fragmentation that results from apoptosis. ${ }^{16}$ To confirm whether asiatic acid induces apoptosis in MIA PaCa-2 cells, the TUNEL assay, western blotting, and annexin $\mathrm{V}$ assay were performed. For the TUNEL assay, MIA PaCa-2 cells were treated with $52.7 \mu \mathrm{M}$ of asiatic acid ( $\mathrm{IC}_{50}$ value) and $5 \mu \mathrm{M}$ HSW354 ( $\mathrm{IC}_{50}$ value), a positive inducer of apoptosis. ${ }^{13}$ Similar to HSW345, asiatic acid induced apoptosis (Fig. 3A). Using western blots, it was found that asiatic acid treatment inhibited the expression of antiapoptotic Bcl-2 and resulted in the cleavage of caspase- 3 and PARP. The expression of PTEN, a protein related to cell cycle control, was biphasically changed depending on concentration (Fig. 3B). The flow cytometry analysis of the cell cycle also showed no significant changes (data not shown). According to the annexin $\mathrm{V}$ assay results, apoptosis rates were increased by asiatic acid (Fig. 3C). Caspase proteins are major mediators of apoptosis and cleaved caspase- 3 is a marker for apoptosis. ${ }^{17}$ These results confirm that asiatic acid induces apoptosis in MIA PaCa-2 cells.

To determine whether asiatic acid induces autophagy in pancreatic cancer cells, levels of autophagy protein markers were determined by using western blotting. Autophagy is the major pathway to eliminate damaged cell organelles or useless proteins. With regard to cancer, autophagy possesses two opposing functions. ${ }^{18,19}$ Autophagy is a tumor suppressor mechanism, whereby the lack of autophagy genes has been shown to promote tumorigenesis. ${ }^{20}$ In contrast, autophagy can contribute to tumor growth by protecting cells from anticancer agents. ${ }^{21-23}$ LC3I is cleaved to form LC3II, which is involved in the formation of autophagosomes; LC3II is considered a marker of autophagy. p38 is a Mitogen-activated protein kinase (MAPK) family member and has been reported to be related to the induction of autophagy. ${ }^{24,25}$ Choi et al. reported that capsaicin-induced p-p38 led to autophagy and regulated autophagosome formation in breast cancer cells. ${ }^{26}$ Decreased mTOR signaling is an important initiator of autophagy to protect the cell from stresses, such as nutrient starvation and low ATP or oxygen levels. The inhibition of mTOR is known to induce early activation of the autophagy cascade, including the formation of autophagosomes. ${ }^{27,28}$ Under insufficient ATP conditions, changes to the intracellular ATP/AMP ratio activates AMPK and phosphorylates tuberous sclerosis complex 2 (TSC2), which results in the inhibition of mTORmediated TSC2. ${ }^{29}$ The protein levels of LC3II, p38, p-p38,
$\mathbf{A}$

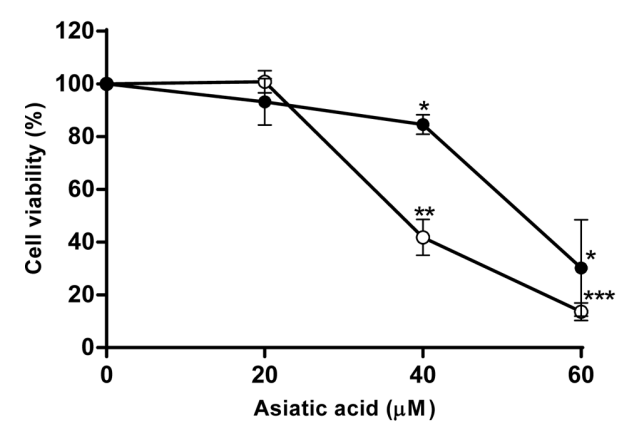

B

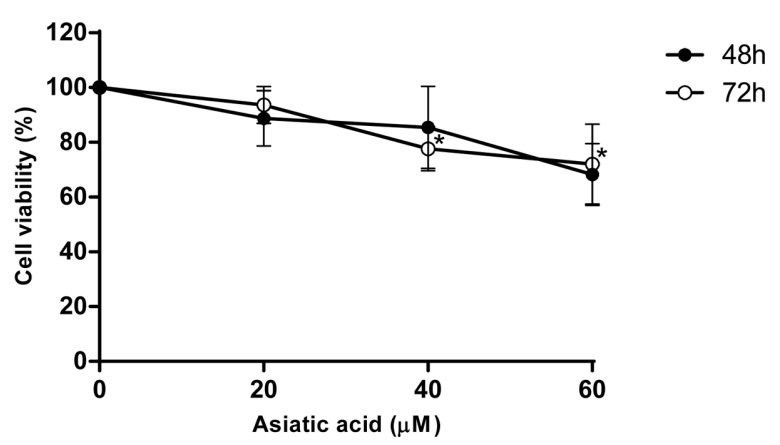

Fig. 2. Asiatic acid inhibits the growth of pancreatic cancer cells. MIA PaCa-2 cells (A) and PANC-1 cells (B) were seeded onto a 96well plate and incubated with $0,20,40$, and $60 \mu \mathrm{M}$ of asiatic acid for 48 (filled circle) and $72 \mathrm{~h}$ (unfilled circle). Cell viability was analyzed using the WST-1 assay and mean values were calculated from triplicate wells. This experiment was repeated three times $\left({ }^{*} p \leq 0.05 ;{ }^{* *} p \leq 0.01 ;{ }^{* * *} p \leq 0.001\right)$. 


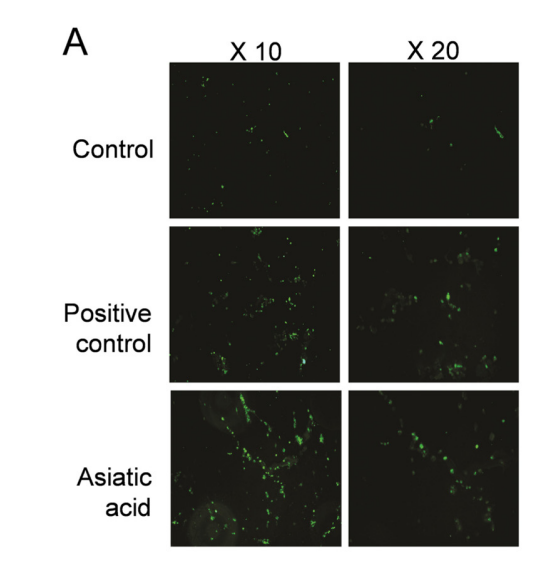

C

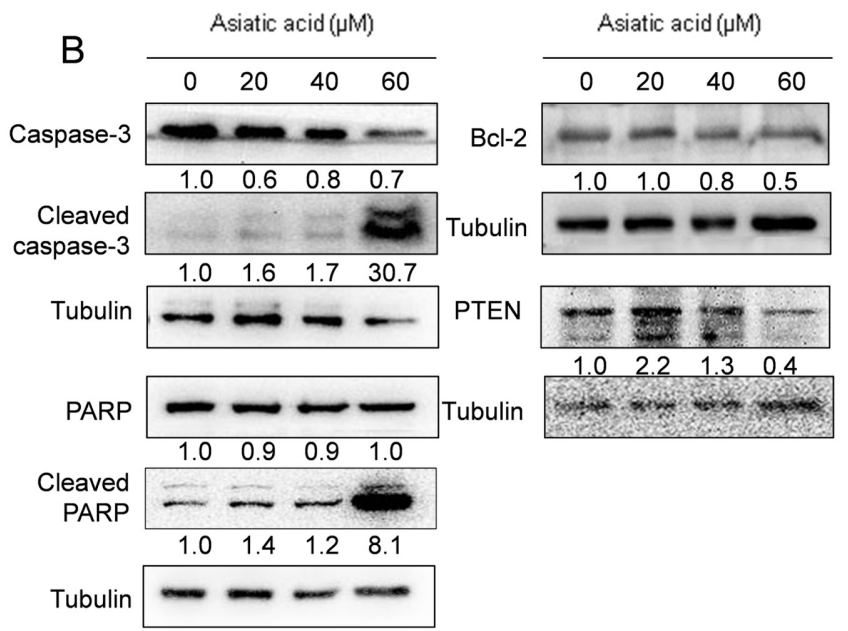

Asiatic acid $(\mu \mathrm{M})$

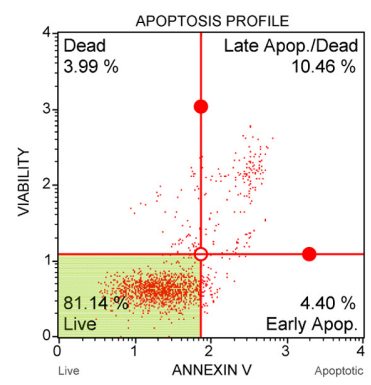

20

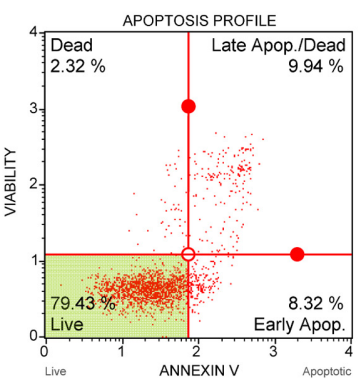

40

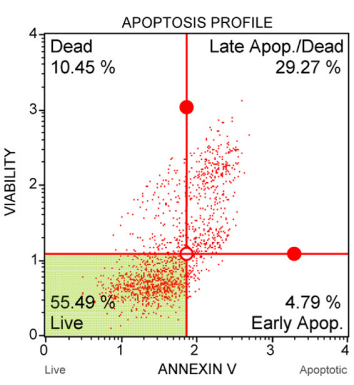

60



Fig. 3. Asiatic acid induces apoptosis in MIA PaCa- 2 cells. (A) The effect of asiatic acid in MIA PaCa- 2 cells using the TUNEL assay. Positive control was HSW345. Cells were photographed at magnifications of 10 and 20X. (B) The effect of asiatic acid on the expression of apoptosis-related proteins in MIA PaCa-2 cells. (C) The effect of asiatic acid on apoptosis in MIA PaCa-2 cells was estimated by annexin V assay.

mTOR, p-mTOR, AMPK, and p-AMPK were examined (Fig. 4). Asiatic acid increased the level of LC3II, a marker of autophagosome formation, as well as the level of p-p38. In addition, the levels of p-mTOR, a negative regulator of autophagy, were decreased by asiatic acid. By contrast, the level of $\mathrm{p}$-AMPK, a positive regulator of autophagy, was increased. Therefore, asiatic acid induced autophagy in MIA PaCa-2 cells through the AMPK/ mTOR pathway.

miRNAs are small, non-coding RNA that play important roles in growth, differentiation, and cell death. ${ }^{30}$ Several miRNAs are differentially expressed in pancreatic cancer. Among them, miR-17 and miR-21 have been reported to be overexpressed in pancreatic cancer. miR-21 has been shown to be overexpressed in early pancreatic tumors and pancreatic cancer-derived cell lines associated with a poor outcome. miR-21 protects pancreatic cancer cells from cell death and inhibition of miR-21 suppresses tumor growth. ${ }^{31}$ miR-17 is a member of the miR-17-92
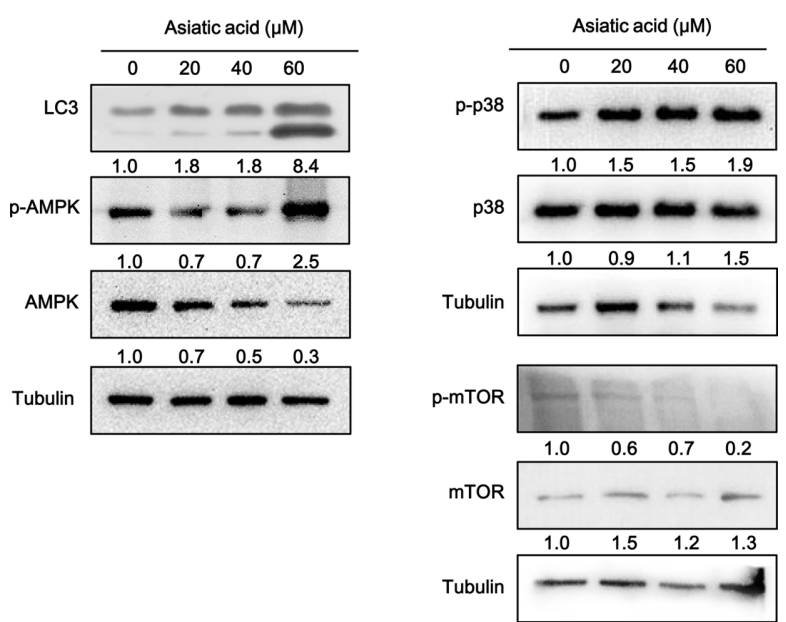

Fig. 4. The effect of asiatic acid on the expression of autophagyrelated proteins in MIA PaCa-2 cells. Western blotting was performed to detect the protein expression of LC-3II, p-AMPK, AMPK, p-p38, p38, p-mTOR, mTOR, and tubulin. Asiatic acid was dissolved in DMSO. MIA PaCa-2 cells were treated with different concentrations of asiatic acid $(0,20,40$ and $60 \mu \mathrm{M})$ for $48 \mathrm{~h}$. Tubulin was used as a loading control and band density was calculated using Image J. 
A

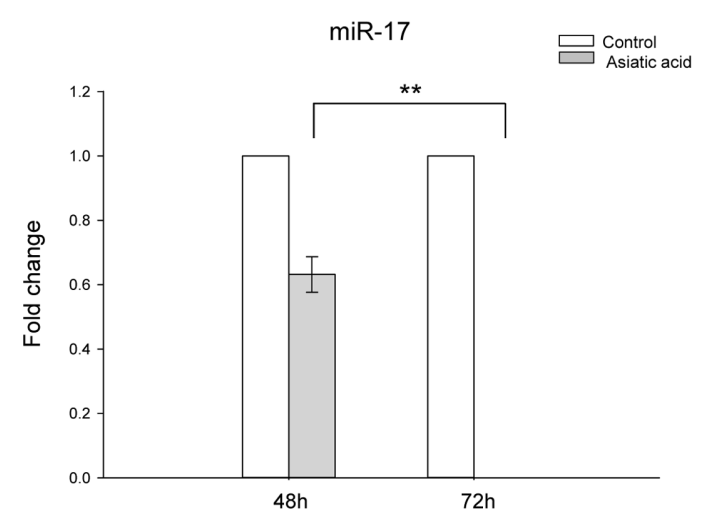

B

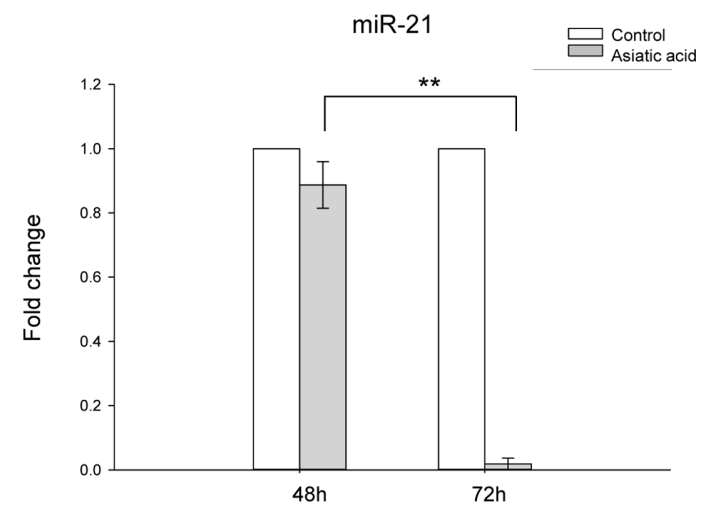

Fig. 5. Expression level of microRNAs in MIA PaCa-2 cells treated with asiatic acid. Cells were treated with $60 \mu \mathrm{M}$ of asiatic acid for 48 and $72 \mathrm{~h}$. The $\mathrm{C}_{\mathrm{T}}$ mean was calculated from three wells and RNU6B was used as a control to determine the relative miRNA expression. The $2^{-\Delta \Delta C T}$ method was used for the relative quantitation of miR-17 (A) and miR-21 (B).

cluster, which is known to act as an oncogene in various cancers, such as breast, colon, lung, and pancreatic cancer. $^{32,33}$ Up-regulated miR-17 promotes pancreatic cancer cell proliferation and invasion. ${ }^{34}$ Using the TaqMan miRNA assay, we found that the expression levels of both miR-17 and miR-21 (Fig. 5A, 5B) were decreased compared to the levels in controls. Asiatic acid significantly reduced the overexpression of miR-17 and miR-21 in pancreatic cancer cells.

Therefore, asiatic acid induces apoptosis and autophagy in pancreatic cancer cell lines and asiatic acid may have potential to be developed as a therapeutic agent for pancreatic cancer.

\section{Acknowledgments}

This article is dedicated to the memory of our esteemed colleague Prof. Eun Joo Lee, a good friend, and talented scientist who prematurely passed away on March 15th, 2018. This research was supported by Wonkwang University in 2017 and the National Research Foundation of Korea grant funded by the Korean Government (NRF2017R1A2B4003403 and NRF-2019R1A6A1A03031807).

\section{References}

(1) Campbell, P. J.; Yachida, S.; Mudie, L. J.; Stephens, P. J.; Pleasance, E. D.; Stebbings, L. A.; Morsberger, L. A.; Latimer, C.; McLaren, S.; Lin, M. L.; McBride, D. J.; Varela, I.; Nik-Zainal, S. A.; Leroy, C.; Jia, M.; Menzies, A.; Butler, A. P.; Teague, J. W.; Griffin, C. A.; Burton, J.; Swerdlow, H.; Quail, M. A.; Stratton, M. R.; Iacobuzio-Donahue, C.; Futreal, P. A. Nature 2010, 467, 1109-1113.

(2) Lee, H. J. Nat. Prod. Sci. 2014, 20, 170-175.

(3) Silverman, D. T.; Schiffman, M.; Everhart, J.; Goldstein, A.; Lillemoe, K. D.; Swanson, G. M.; Schwartz, A. G.; Brown, L. M.;
Greenberg, R. S.; Schoenberg, J. B.; Pottern, L. M.; Hoover, R. N.; Fraumeni jr, J. F. Jr. Br. J. Cancer 1999, 80, 1830-1837.

(4) Strimpakos, A.; Saif, M. W.; Syrigos, K. N. Cancer Metastasis Rev. 2008, 27, 495-522.

(5) Kokubo, M.; Nishimura, Y.; Shibamoto, Y.; Sasai, K.; Kanamori, S.; Hosotani, R.; Imamura, M.; Hiraoka, M. Int. J. Radiat. Oncol. Biol. Phys. 2000, 48, 1081-1087.

(6) Burris, H. A., 3rd; Moore, M. J.; Andersen, J.; Green, M. R.; Rothenberg, M. L.; Modiano, M. R.; Cripps, M. C.; Portenoy, R. K.; Storniolo, A. M.; Tarassoff, P.; Nelson, R.; Dorr, F. A.; Stephens, C. D.; Von Hoff, D. D. J. Clin. Oncol. 1997, 15, 2403-2413.

(7) Howes, M. J.; Houghton, P. J. Pharmacol. Biochem. Behav. 2003, 75, 513-527.

(8) Huang, F. X.; Lin, X. H.; He, W. N.; Song, W.; Ye, M.; Yang, W. Z.; Guo, D. A. J. Asian Nat. Prod. Res. 2012, 14, 1039-1045.

(9) Guo, F. F.; Feng, X.; Chu, Z. Y.; Li, D. P.; Zhang, L.; Zhang, Z. S. J. Asian Nat. Prod. Res. 2013, 15, 15-21.

(10) Lee, Y. S.; Jin, D. Q.; Kwon, E. J.; Park, S. H.; Lee, E. S.; Jeong, T. C.; Nam, D. H.; Huh, K.; Kim, J. A. Cancer Lett. 2002, 186, 83-91.

(11) Bunpo, P.; Kataoka, K.; Arimochi, H.; Nakayama, H.; Kuwahara, T.; Vinitketkumnuen, U.; Ohnishi, Y. J. Med. Invest. 2005, 52, 65-73.

(12) Kavitha, C. V.; Agarwal, C.; Agarwal, R.; Deep, G. PloS one 2011, 6, e22745.

(13) Seo, J. H.; Jung, K. H.; Son, M. K.; Yan, H. H.; Ryu, Y. L.; Kim, J.; Lee, J. K.; Hong, S.; Hong, S. S. Cancer Lett. 2013, 338, 271-281.

(14) Tang, X. L.; Yang, X. Y.; Jung, H. J.; Kim, S. Y.; Jung, S. Y.; Choi, D. Y.; Park, W. C.; Park, H. Biol. Pharm. Bull. 2009, 32, 1399-1405.

(15) Wu, Q.; Lv, T.; Chen, Y.; Wen, L.; Zhang, J.; Jiang, X.; Liu, F. Mol. Med. Rep. 2015, 12, 1429-1434.

(16) Lozano, G. M.; Bejarano, I.; Espino, J.; González, D.; Ortiz, A.; García, J. F.; Rodriguez, A. B.; Pariente, J. A. J. Reprod. Dev. 2009, 55, 615-621.

(17) Kaufmann, S. H.; Desnoyers, S.; Ottaviano, Y.; Davidson, N. E.; Poirier, G. G. Cancer Res. 1993, 53, 3976-3985.

(18) Ogier-Denis, E.; Codogno, P. Biochim. Biophys. Acta 2003, 1603, 113-128.

(19) Hippert, M. M.; O'Toole, P. S.; Thorburn, A. Cancer Res. 2006, 66, 9349-9351.

(20) Qu, X.; Yu, J.; Bhagat, G.; Furuya, N.; Hibshoosh, H.; Troxel, A.; Rosen, J.; Eskelinen, E. L.; Mizushima, N.; Ohsumi, Y.; Cattoretti, G.; Levine, B. J. Clin. Invest. 2003, 112, 1809-1820. 
(21) Apel, A.; Herr, I.; Schwarz, H.; Rodemann, H. P.; Mayer, A. Cancer Res. 2008, 68, 1485-1494.

(22) Degenhardt, K.; Mathew, R.; Beaudoin, B.; Bray, K.; Anderson, D.; Chen, G.; Mukherjee, C.; Shi, Y.; Gélinas, C.; Fan, Y.; Nelson, D. A.; Jin, S.; White, E. Cancer cell 2006, 10, 51-64.

(23) Chresta, C. M.; Davies, B. R.; Hickson, I.; Harding, T.; Cosulich, S.; Critchlow, S. E.; Vincent, J. P.; Ellston, R.; Jones, D.; Sini, P.; James, D.; Howard, Z.; Dudley, P.; Hughes, G.; Smith, L.; Maguire, S.; Hummersone, M.; Malagu, K.; Menear, K.; Jenkins, R.; Jacobsen, M.; Smith, G. C.; Guichard, S.; Pass, M. Cancer Res. 2010, 70, 288-298.

(24) Comes, F.; Matrone, A.; Lastella, P.; Nico, B.; Susca, F. C.; Bagnulo, R.; Ingravallo, G.; Modica, S.; Lo Sasso, G.; Moschetta, A.; Guanti, G.; Simone, C. Cell Death Differ. 2007, 14, 693-702.

(25) Casas-Terradellas, E.; Tato, I.; Bartrons, R.; Ventura, F.; Rosa, J. L. Biochim. Biophys. Acta Mol. Cell Res. 2008, 1783, 2241-2254.

(26) Choi, C. H.; Jung, Y. K.; Oh, S. H. Mol. Pharmacol. 2010, 78, 114125 .

(27) Tavazoie, S. F.; Alvarez, V. A.; Ridenour, D. A.; Kwiatkowski, D. J.; Sabatini, B. L. Nat. Neurosci. 2005, 8, 1727-1734.

(28) Fitzwalter, B. E.; Thorburn, A. FEBS J. 2015, 282, 4279-4288.

(29) Crino, P. B. Nat. Rev. Neurol. 2016, 12, 379-392.
(30) Cheng, A. M.; Byrom, M. W.; Shelton, J.; Ford, L. P. Nucleic Acids Res. 2005, 33, 1290-1297.

(31) du Rieu, M. C.; Torrisani, J.; Selves, J.; Al Saati, T.; Souque, A.; Dufresne, M.; Tsongalis, G. J.; Suriawinata, A. A.; Carrère, N.; Buscail, L.; Cordelier, P. Clin. Chem. 2010, 56, 603-612.

(32) O'Donnell, K. A.; Wentzel, E. A.; Zeller, K. I.; Dang, C. V.; Mendell, J. T. Nature 2005, 435, 839-843.

(33) Volinia, S.; Calin, G. A.; Liu, C. G.; Ambs, S.; Cimmino, A.; Petrocca, F.; Visone, R.; Iorio, M.; Roldo, C.; Ferracin, M.; Prueitt, R. L.; Yanaihara, N.; Lanza, G.; Scarpa, A.; Vecchione, A.; Negrini, M.; Harris, C. C.; Croce, C. M. Proc. Natl. Acad. Sci. U. S. A. 2006, 103, 2257-2261.

(34) Yu, J.; Ohuchida, K.; Mizumoto, K.; Fujita, H.; Nakata, K.; Tanaka, M. Cancer Biol. Ther. 2010, 10, 748-757.

Received October 21, 2019

Revised November 26, 2019 Accepted November 29, 2019 